\author{
B. Naidych ${ }^{1}$, O. Kostyuk ${ }^{1,2}$
}

\title{
The Substitution Effects on Structural and Electronic Parameters of PbTe-Based Solid Solutions
}

\author{
${ }^{l}$ Vasyl Stefanyk Precarpathian National University, Ivano-Frankivsk, Ukraine,: bvolochanska@i.ua \\ ${ }^{2}$ Ivano-Frankivsk National Medical University, Ivano-Frankivsk, Ukraine, oksanakostuk@gmail.com
}

\begin{abstract}
The paper presents the results of calculations from the first principles of crystallographic parameters and density of electronic states of crystalline semiconductor compounds $\mathrm{PbTe}$ and solid solution $\mathrm{Pb}_{0.97} \mathrm{Cd}_{0.03} \mathrm{Te}$. The approximation of the density functional theory is used and the contribution of cadmium atoms to the density of electronic states is investigated. For solid solutions, model clusters were constructed for all possible positions of cadmium atoms during the substitution of lead in the basic structure, and a quantum chemical calculation of the equilibrium positions of atoms has been performed. Chemical bonds in optimized structures according to the constructed spatial maps of electric charge distribution is analyzed.
\end{abstract}

Keywords: density functional theory, solid solution, $\mathrm{Pb}_{0.97} \mathrm{Cd}_{0.03} \mathrm{Te}$, charge distribution map.

Received 17 May 2020; Accepted 15 June 2020.

\section{Introduction}

Solid solutions based on compounds II-VI and IV-VI are of considerable scientific interest [1-2]. First of all, their use is caused by the high efficiency and quality of thermoelectric and detector materials [3]. Not only independent binary compounds, but also solid solutions, layered structures, quantum dots have become widely used. Such variety of structures are due to the possibility of obtaining fundamentally new materials with excellent properties. In this case, the study should begin with an analysis of the microstructure at the junction of the two materials.

The assessment of the technological conditions and physicochemical characteristics of finished materials is made using of techniques proposed by quantum chemistry. At the same time, it is relatively inexpensive and quite accurate. Since the key approaches are using of density functional theory [4], and the crystallographic, energy and thermodynamic parameters determined by such methods satisfy the accuracy requirements [1], the current study is performed within these approaches.

$\mathrm{PbTe}-\mathrm{CdTe}$ solid solutions are in great research interest due to the possibility of using synthesized materials as n- and p-legs of the thermoelectric medium- temperature generated modules [5], in miniature devices or flexible systems, thermoelectric micromodules or micro-sized coolers [6]. At a Cd content of up to $11 \%$, the compound is characterized by the structure of $\mathrm{NaCl}$ [7-8] and a linear decrease in the constant crystal lattice from $6.462 \AA$ to $6.414 \AA[1,9]$. For the investigated composition of the crystal lattice constant should be $6.444 \AA$. When crystals are growing by the method of Physical Vapor Transport, the number of internodal cadmium atoms is much smaller than in the Bridgman method [9]. In the case of thin films are grown by open evaporation in vacuum, the structure is homogeneous and no significant number of defects is found, which may indicate the identification of interstitial atoms or compounds in the crystal lattice of sphalerite (which would indicate the inclusion of CdTe) [10]. Solid solutions of $\mathrm{Pb}_{1-\mathrm{x}} \mathrm{Cd}_{\mathrm{x}} \mathrm{Te}$ are characterized by an increase in the band gap compared to the basic structure of $\mathrm{PbTe}$, which increases with increasing cadmium content [5]. For the compound $\mathrm{Pb}_{0.97} \mathrm{Cd}_{0,03} \mathrm{Te}$, the band gap is $0.32 \mathrm{eV}$, which leads to an increase in the Seebeck coefficient due to an increase in the density-of-states effective mass of n-type PbTe [5].

Information about the distribution of electrons in the energy spectrum of the crystal is crucial when analyzing 
the chemical bonds in a compound [11-12]. Solid solutions are also interesting in that due to the formation of combined types of bonds there are local areas with different properties. It is necessary to anticipate the nature of the change in the properties of the resulting condensate, which will primarily be determined by the length and type of bonds formed.

\section{Calculation methods}

Calculations by ab initio methods of equilibrium positions of atoms in the structure, electron density distribution, total energy and frequencies and oscillation spectra of binary and ternary compounds based on lead chalcogenides are performed using the Becke-Lee-YangParr exchange correlation functional (B3LYP) [13] and basic set Stevens-Basch-Krauss-Jasien-Cundari (SBKJC) [4].

The exchange-correlation functional is determined by the local electron density and its gradient [14]. The electron density gradient is a local quantity and is used to describe nonlocal effects. The energies of individual atoms are determined from the total energy by distributing the local electron density and the local density gradient. Under the Kohn-Sham approach, electron energy is expressed through the kinetic energy of noninteracting electrons $T_{S}[\rho]$, the energy of attraction between the nucleus and the electron $E_{n e}[\rho]$, the classical Coulomb interaction $E_{C L B}[\rho]$ and exchange-correlation energy, which includes selfinteraction correction and the difference between real kinetic energy $T_{S}[\rho]$ :

$$
E_{E L C}[\rho]=T_{S}[\rho]+E_{n e}[\rho]+E_{C L B}[\rho]+E_{X C}[\rho] .
$$

Hybrid exchange-correlation functional B3LYP $[13,15]$ is expressed through the components:

$$
E_{X C}^{B 3 L Y P}=a E_{X}^{E X C}+(1-a) E_{X}^{S L T}+b E_{X}^{B 88}+(1-c) E_{C}^{V W N}+c E_{C}^{L Y P},
$$

where $E_{X}^{E X C}-$ Hartree-Fock exchange functional, $E_{X}^{S L T}-$ Slater exchange functional, $E_{X}^{B 88}$ - Becke exchange functional, $E_{C}^{V W N}-$ Vosco-Wilk-Nussair correlation component, $E_{C}^{L Y P}$ - Lee-Yang-Parr correlation functional.

The equilibrium positions of atoms in the structure in the absence and alternate placement of cadmium atoms in the position of lead on the surface and inside the model cluster were calculated. The clusters for the calculation of the studied properties consisted of 64 atoms, which corresponds to an elementary cubic cell. The calculation of the equilibrium positions of atoms in the structure corresponding to the minima on the surface of the potential energy is performed by constructing a Hessian matrix of the second derivatives of the total energy of the clusters. After that, energy parameters were calculated for the optimized structure. To assess the modification of the electron spectrum, the distribution of the total density of electronic states and partial contributions from metal atoms and chalcogen were

analyzed. Visualization of the obtained results of calculations from the first principles was carried out in the Chemcraft.

The determination of the stability of the system is based on the comparison of the enthalpy of formation of a solid solution at different positions of atoms. In the General case, the enthalpy of the doped compound is defined [16] as:

$$
\Delta H_{f}=\frac{E_{3 a 2}^{P b_{1-x} C d_{x} T e}-a E_{\kappa p}^{P b}-b E_{\kappa p}^{T e}-c E_{\kappa p}^{C d}}{a+b+c},
$$

where $E_{3 a z}^{P b_{1-x} C d_{x} T e}$ is the energy of the cell (cluster), a, b, c are the number of $\mathrm{Pb}, \mathrm{Te}$ and $\mathrm{Cd}$ atoms that form the cluster, $E_{k p}^{P b}, E_{\kappa p}^{T e} i E_{k p}^{C d}$ is the energy of the corresponding atoms in the solid state.

The binding energy of atoms is released during the formation of a compound from individual atoms. It can be determined from the following ratio:

$$
\Delta E_{36}=\frac{E_{3 a z}^{P b_{a} C d_{b} T e_{c}}-a E_{a m}^{P b}-b E_{a m}^{C d}-c E_{a m}^{T e}}{a+b+c},
$$

where $E_{a m}^{P b}, E_{a m}^{C d} i E_{a m}^{T e}$ - energies of the corresponding isolated atoms. The greater the absolute value of the binding energy, the more stable the structure and the stronger the binding forces between the atoms. A negative sign also indicates the stability of the formed compound.

\section{Results and Discussion}

The displacement of atoms in a solid solution is caused by the redistribution of charge in the vicinity of the cadmium atom. Due to the fact that cadmium is free of all orbitals of the upper levels except 2 s, electrons can flow to these orbitals. On charge distribution maps for a cadmium-containing crystal lattice, a region with a higher gradient is formed around it, and areas distant from it are characterized by a more uniform distribution.

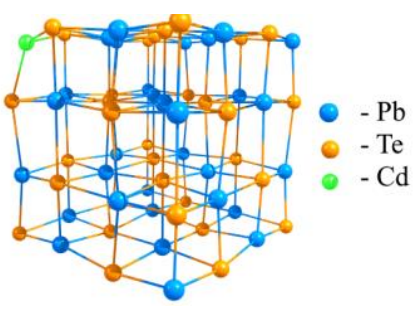

A

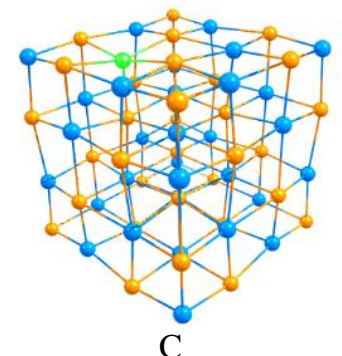

Fig. 1. Cluster models for $\mathrm{Pb}_{0.97} \mathrm{Cd}_{0,03} \mathrm{Te}$ solid solution when placing a cadmium atom in the crystal lattice point: A) three-, B) four-, C) five- and D) sixcoordinated lead atoms. 
Crystal structure does not significantly change due to the close values of the ionic radii of cadmium and tellurium, but their introduction into the model cluster can leads to minor changes in the structure. Depending on the position of the cadmium atom, the parameters of the crystal lattice of the basic structure will change. Table 1 shows the values of the crystal lattice constants for the investigated solid solution.

Comparison of the total energies of model clusters (Fig. 1) that reproduce the composition of the solid solution $\mathrm{Pb}_{0.97} \mathrm{Cd}_{0.03} \mathrm{Te}$ at the position of the cadmium atom in the lead site shows that the energies of clusters with tricoordinated and sixcoordinated cadmium atoms are the lowest and differ by $0.125 \mathrm{eV}$. The lowest energy is in clusters, where the cadmium atom replaces the lead inside the structure (the cadmium atom forms six bonds with the tellurium atoms). This is due to the fact that in such a structure the least degree of distortion, because the symmetrical surroundings of the cadmium atom allows to form structures with the least displacement of atoms due to substitution between metal atoms.

The introduction of cadmium atoms in the crystal lattice with an ionic bond type, which form mixed ioncovalent bonds with tellurium, leads to a change in the intensity of isolines on the charge distribution map. The increase in electron density is due to the contribution of the covalent component of the Cd-Te bonds.

The electron density distribution in a cluster consisting of lead and tellurium atoms is qualitatively different from the case when in the base compound the

Table 1

Total energies of clusters and crystal lattice steels at different positions of the cadmium impurity atom

\begin{tabular}{|l|c|c|c|c|}
\hline & \multicolumn{4}{|c|}{ The cluster model from Fig. 1 } \\
\cline { 2 - 5 } & $\mathrm{A}$ & $\mathrm{B}$ & $\mathrm{C}$ & $\mathrm{D}$ \\
\hline Lattice constant, a, $\AA$ & 6.45980 & 6.42835 & 6.44442 & 6.44346 \\
\hline Cluster energy, keV & 14.600843 & 14.601094 & 14.60089 & 14.600718 \\
\hline
\end{tabular}
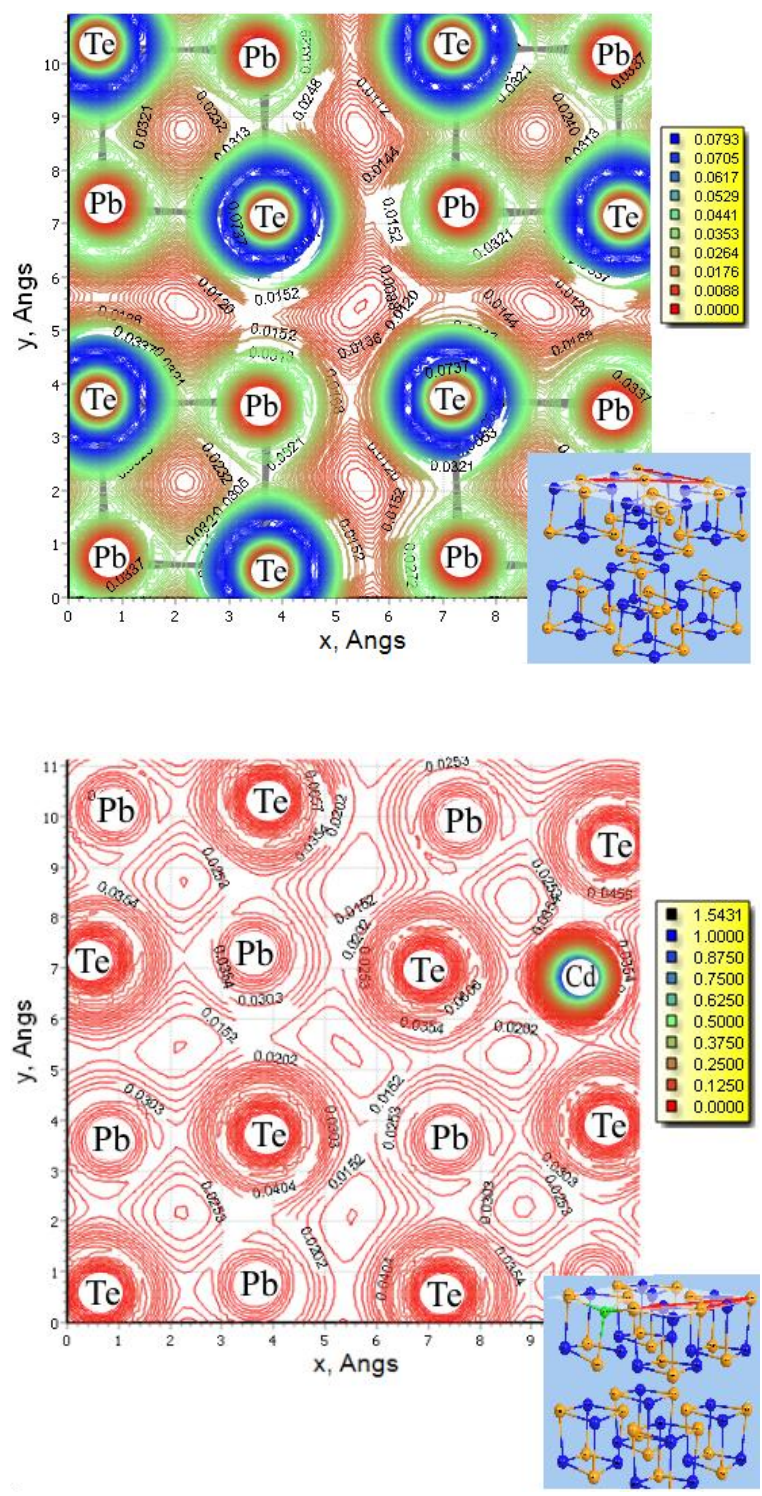
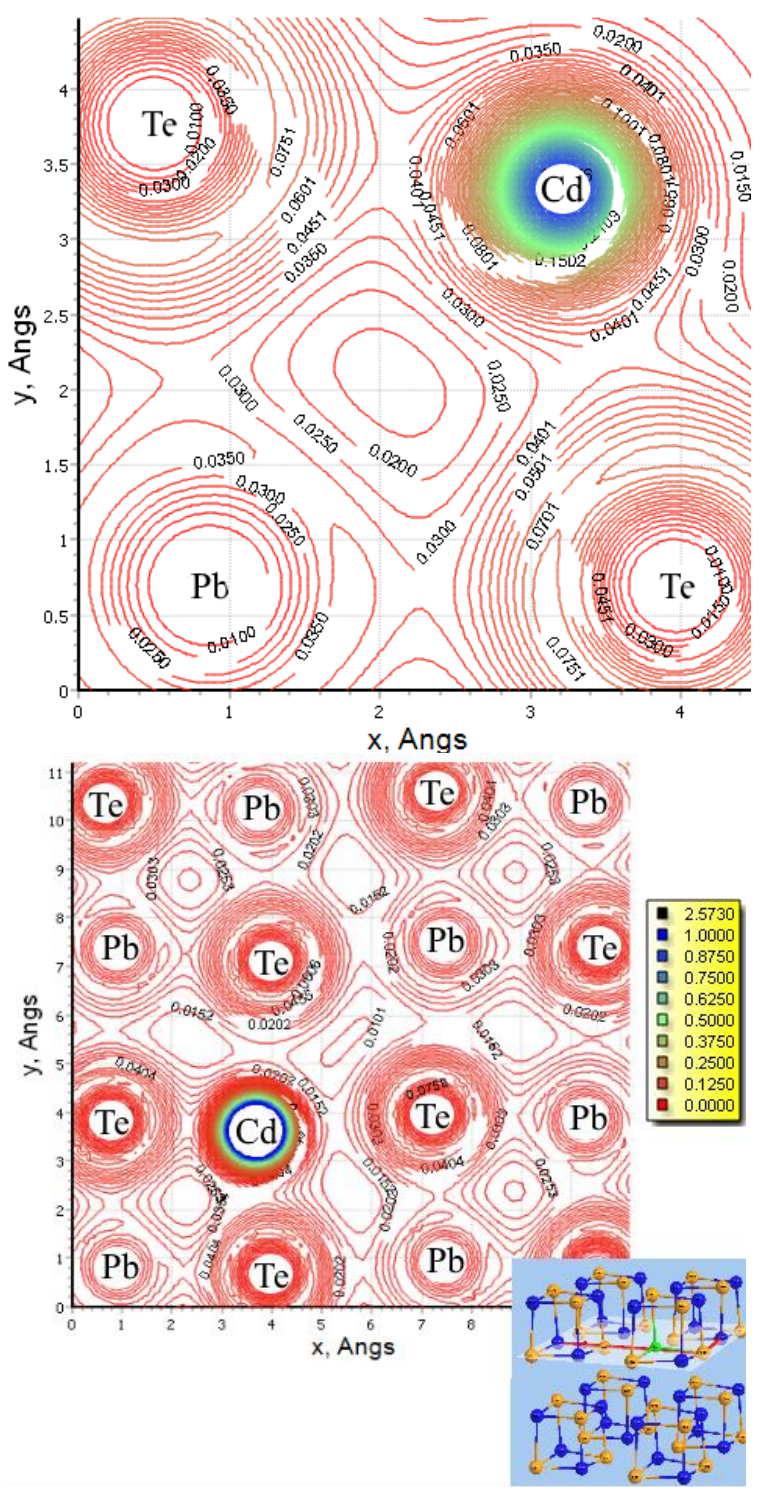

Fig. 2. Spatial maps of electric charge distribution in model clusters. 
cadmium atom is located in the nodal position of one of the lead atoms (Fig. 2). In a binary compound, the minimum electron density is 0.0088 and the maximum value is 0.0793 . Substitution of metal atoms leads to an increase in the minimum value of density to 0.125 and in the maximum value to 2.573. Comparing the electron density distribution in these compounds makes it possible to analyze the nature of the chemical bonds in the formation of solid solutions. The similarity of the electron density distribution around metal and chalcogen atoms and the presence of electron cloud deformation along the bond line in lead telluride indicate the predominance of the ionic bond type. A marked increase in the intensity of the lines around the cadmium is the result of a much lower electronegativity, and therefore the bonds will have higher percentage of covalence. Due to the difference between the sizes of cadmium and lead atoms, in the vicinity of the lead sites, where the substitution occurs, there are areas with local elastic
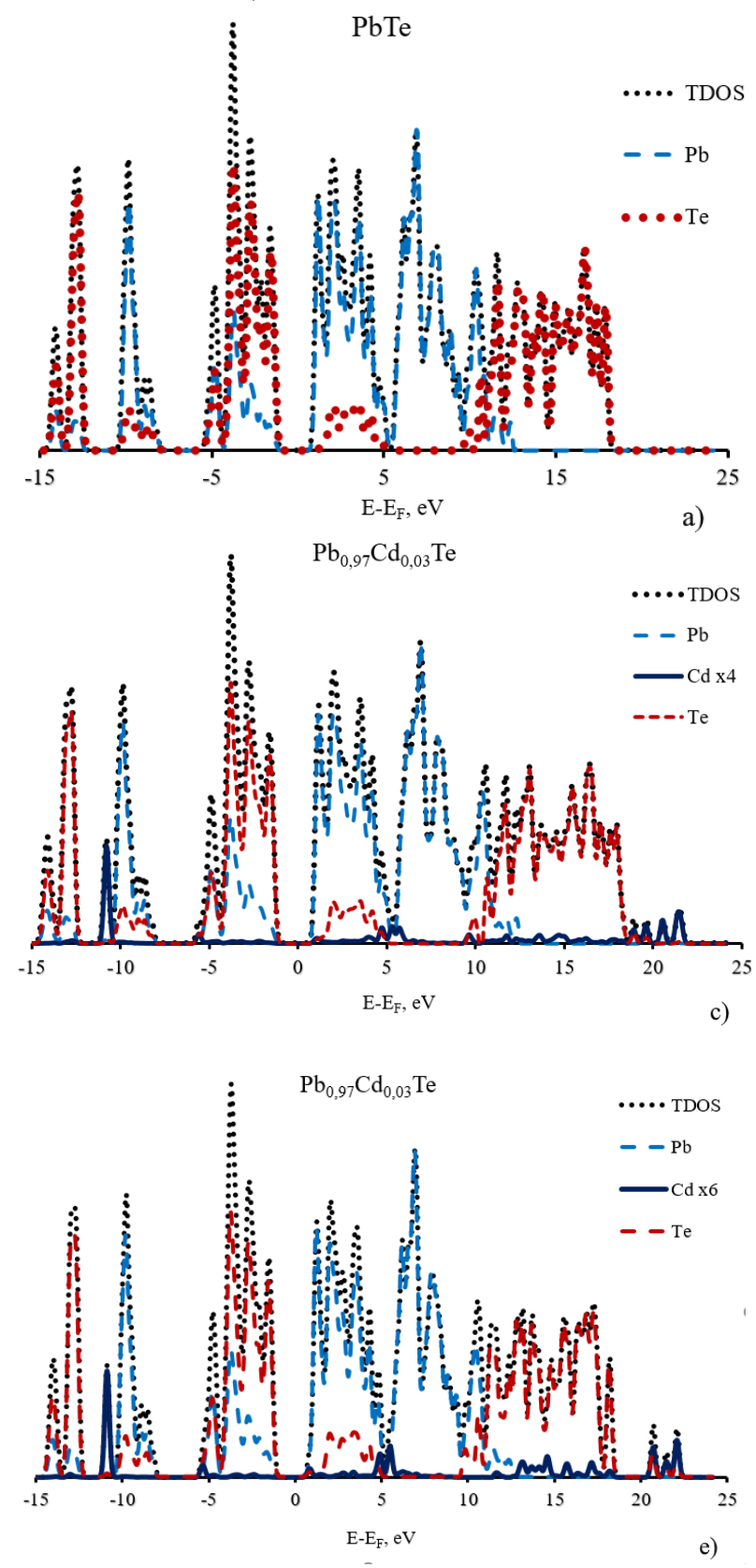

deformations. The nature of the crystalline orbitals that make up the valence band and the conduction band is determined from the partial contributions of atoms in impurity-free lead telluride and during the substitution of lead atoms in the corresponding positions. The contributions of cadmium atoms are highlighted separately on DOS charts (Fig. 3). Analyzing the difference between binary and ternary compounds, the following changes in the energy spectrum are observed. The valence band and the conduction band consist of three subbands. The third subband of the filled levels consists of predominant contributions from tellurium and lead atoms, regardless of whether there is an impurity in the crystal under study. In the second subzone, the predominant contribution belongs to the lead atoms. In the third - the first peak is composed equally of the levels of both lead and tellurium atoms, and in the following the
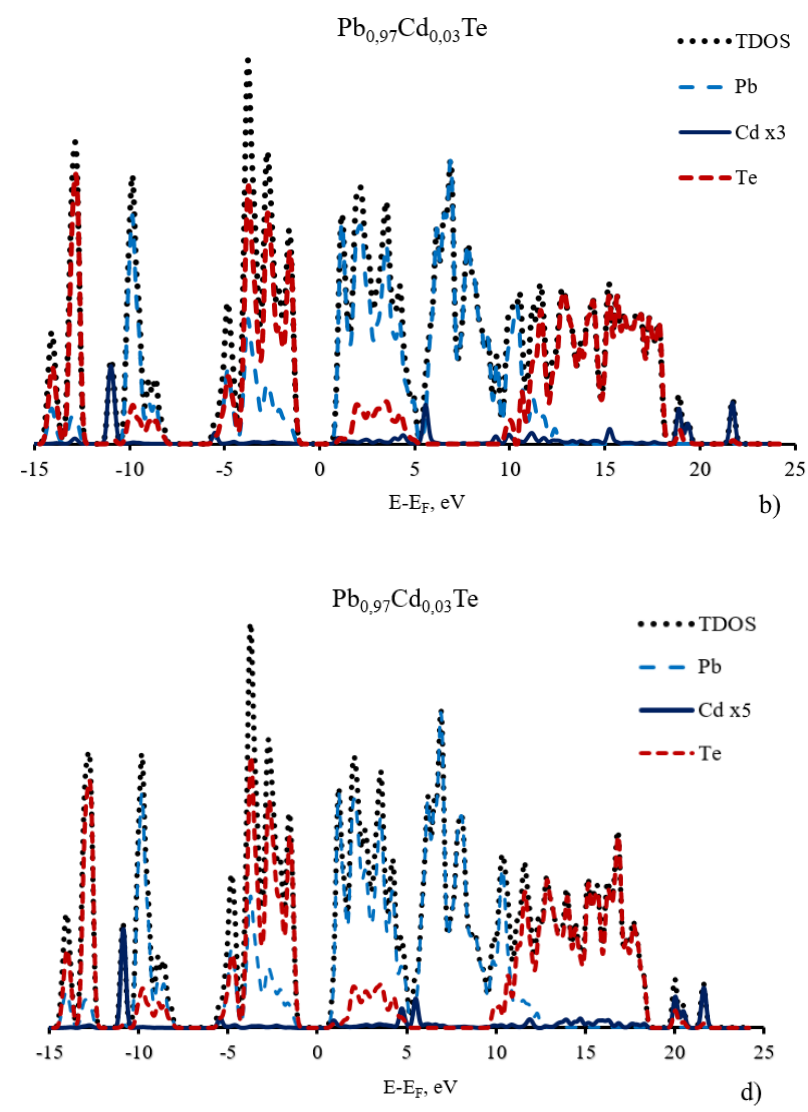

Fig. 3. The calculated density of electronic states of PbTe (a) and $\mathrm{Pb}_{0.97} \mathrm{Cd}_{0.03} \mathrm{Te}$ clusters when cadmium fills lead sites in three- (b), four- (c) b five- (d) and sixcoordinated (e) atoms. 
contribution of chalcogen is more significant. Cadmium forms an additional level in the second subband of the valence band and makes small contributions in each of the subbands of the conduction band.

\section{Conclusions}

The use of the density functional theory allows to model the crystal structure of both binary compounds of chalcogenide crystals and to study the change of the main crystallographic and band parameters due to the formation of solid solutions. Analysis of electron density distribution maps allows to estimate the causes of lattice deformations and to predict their most probable positions.

The formation of a solid solution of $\mathrm{Pb}_{0.97} \mathrm{Cd}_{0.03} \mathrm{Te}$ leads to a decrease in the crystal lattice parameter comparing to the basic structure of PbTe. Clusters have the lowest energy if the lead atom is substituted within the structure if it forms six bonds with tellurium.

The cadmium atom in the lead vacancy causes a local change in the electron density distribution due to the presence of a covalent component in the $\mathrm{Cd}-\mathrm{Te}$ bond. The presence of cadmium in the crystal lattice of lead telluride leads to the formation of an additional level in the valence band and insignificant contributions in the conduction band.

This study was supported by the Ministry of Education and Science of Ukraine as the project for young scientists "Technology of thin-film thermoelectric micromodules based on multicomponent compounds with quantum-size effects" (0119U100062).

Naidych B. - Ph.D (Physics and Mathematics), Researcher of the Department of Physics and Chemistry of Solid State;

Kostyuk O. - Ph.D (Physics and Mathematics), Assistant of the Department of Medical Informatics, Medical and Biological Physics, Senior Researcher.

[1] M. Bukała, P. Sankowski, R. Buczko, P. Kacman, Physical Review B 86, 085205 (2012) (DOI:10.1103/PhysRevB.86.085205).

[2] S. Kumar, Z.H. Khan, M.M. Khan, M. Husain, Current Applied Physics 5, 561 (2005) (DOI:10.1016/j.cap.2004.07.001).

[3] K. Ahn, K. Biswas, J. He, I. Chung, V. Dravidb, M. G. Kanatzidis, Energy \& Environmental Science (2013) (DOI:10.1039/c3ee40482j).

[4] M.S. Gordon, M.W. Schmidt, in Theory and Applications of Computational Chemistry, the first forty years, Chapter 41, eds. by C. E. Dykstra, G. Frenking, K.S. Kim, G.E. Scuseria (Elsevier, Amsterdam, 2005) (DOI:10.1016/b978-044451719-7/50084-6).

[5] G. Tan, X. Zhang, S. Hao, H. Chi, T. P. Bailey, X. Su, C. Uher, V. P. Dravid, C. Wolverton, M.G. Kanatzidis, ACS applied materials \& interfaces 11, 9197 (2019) (DOI:10.1021/acsami.8b21524).

[6] Y. Pei, A.D. LaLonde, N.A. Heinz, X. Shi, Sh. Iwanaga, H. Wang, L. Chen, G.J. Snyder, Advanced Materials 23(47), 5674 (2011) (DOI:10.1002/adma.201103153).

[7] R. Minikayev, E. Dynowska, P. Dziawa, E. Kamińska, A. Szczerbakow, in VIII KSUPS 2009: Extended Abstracts / Synchrotron Radiation in Natural Science 8, 83 (2009).

[8] R. Kuna, S. Adamiak, S. Petit, P. Baroni, K. Gas, R. Minikayev, A. Szczerbakow, J. Łażewski, W. Szuszkiewicz, Acta Physica Polonica A 130(5), 1245 (2016) (DOI:10.12693/APhysPolA.130.1245).

[9] M. Szot, A. Szczerbakow, K. Dybko, L. Kowalczyk, E. Smajek, V. Domukhovski, E. Łusakowska, P. Dziawa, A. Mycielski, T. Story, M. Bukała, M. Galicka, P. Sankowski, R. Buczko, P. Kacman, Acta Physica Polonica A 116(5), 959 (2009) (DOI:10.12693/APhysPolA.116.959).

[10] K.V. Rani, S.A. Mary, S.A. Raj, Asian Journal of Applied Sciences 7(8), 768 (2014) (DOI:10.3923/ajaps.2014.768.773).

[11] L.I. Nykyruy, B.P. Naidych, O.M. Voznyak, T.O. Parashchuk, R.V. Ilnytskyi, Semiconductor Physics, Quantum Electronics \& Optoelectronics 22(2), 156 (2019) (DOI:10.15407/spqeo22.02.156).

[12] B.P. Naidych, Physics and Chemistry of Solid State 19(3), 254 (2018) (DOI:10.15330/pcss.19.3.254-257).

[13] A.D. Becke, J. Chem. Phys. 98, 5648 (1993) (DOI:10.1063/1.464913).

[14] H. Nakai, Chemical Physics Letters 363, 73 (2002) (DOI:10.1016/s0009-2614(02)01151-x).

[15] C. Lee, W. Yang, R. G. Parr, Phys. Rev. B 37, 785 (1988) (DOI:10.1103/PhysRevB.37.785).

[16] C. Peng, L. Zeng, F. Huang, M. Zhong, S. Liang, X. Ran, L. Zhou, IOP Conf. Series: Materials Science and Engineering 772, 012064 (2020) (DOI:10.1088/1757-899X/772/1/012064). 
The Substitution Effects on Structural and Electronic Parameters...

\author{
Б. Найдич ${ }^{1}$, О.Костюк $^{1,2}$
}

\title{
Вплив заміщення на структурні та електронні параметри твердих розчинів на основі плюмбум телуриду
}

\author{
${ }^{1}$ ДВНЗ «Прикарпатський національний університет імені Василя Стефаника», Івано-Франківськ, Украӥна, \\ bvolochanska@i.ua \\ ${ }^{2}$ Івано-Франківський національний медичний університет, Івано-Франківськ, Украйна,
}

В роботі представлено результати розрахунків із перших принципів кристалографічних параметрів та густини електронних станів кристалічних напівпровідникових сполук $\mathrm{PbTe} \mathrm{i}$ твердого розчину $\mathrm{Pb}_{0,97} \mathrm{Cd}_{0,03} \mathrm{Te}$. Використано наближення теорії функціоналу густини і досліджено внесок атомів кадмію в густину електронних станів. Для твердих розчинів побудовано модельні кластери для всіх можливих положень атомів кадмію при заміщенні плюмбуму в базовій структурі та проведено квантово-хімічний розрахунок рівноважних положень атомів. Здійснено аналіз хімічних зв'язків у оптимізованих структурах згідно побудованих просторових карт розподілу електричного заряду.

Ключові слова: теорія функціоналу густини, твердий розчин, $\mathrm{Pb}_{0,97} \mathrm{Cd}_{0,03} \mathrm{Te}$, карта розподілу заряду. 